\title{
ANALISIS KUALITAS PRODUKSI TEMPE DENGAN METODE SEVEN TOOLS DI UD MAJU JAYA.
}

\author{
Wahyu binti Madeali \\ Dosen fakultas Teknik Universitas Pamulang \\ Dosen2342@unpam.ac.id
}

\begin{abstract}
ABSTRAK
Era globalisasi menyajikan kenyataaan baru yang ditandai oleh pasar tanpa batas negara, revolusi teknologi informasi dan pelayanan UD Maju Jaya adalah perusahaan yang bergerak di bidang kuliner produk yang diproduksi ialah tempe. Perusahaan ini berdiri dari kecil hingga berkembang seperti saat ini, perusahaan kuliner pada saat ini sedang popular apalagi di kota-kota besar di Indonesia. UD Maju Jaya pernah mengalami masalah kualitas produk pada tahun 2013 dimana kualitas tempe yang di hasilkan tidak sesuai yang ingin di capai dan kejadian ini berdampak yang negatif bagi perusahaan. Berdasarkan kejadian diatas maka penelitian terhadap kualitas tempe yang merupakan sumber sebagai bahan penelitian. Maka penelitian ini mengambil judul "Analisis Kualitas Produksi Tempe Dengan Metode Seven Tools di UD Maju Jaya."
\end{abstract}

Kata Kunci: Kualitas, Seven Tools, Mutu

\section{I.PENDAHULUAN}

Gelombang globalisasi ekonomi akibat WTO dan sebagainya telah menciptakan tantangan bisnis semakin besar, yaitu kompetisi (competition) yang semakin tinggi, teknologi (technology) yang semakin canggih, peraturan dan perundang-undangan (legislation) yang lebih ketat. Proteksi yang sebelumnya menjadi benteng bagi produk dalam negeri akan hilang diterjang arus liberalisasi, produk dari luar negeri akan bebas masuk ke pasar domestik yang merupakan bagian dari pasar global.

Era globalisasi menyajikan kenyataaan baru yang ditandai oleh pasar tanpa batas negara, revolusi teknologi informasi dan pelayanan. Konsumen tidak tergerak dengan imbauan untuk membeli dan menggunakan produk dalam negeri. Walaupun yang kita ketahui sebagian produk indonesia mempunyai kualitas yang bagus. Karena tantangan dalam dunia bisnis maka pelaku bisnis maupun produsen pada dua pilihan, yaitu masuk dalam arena kompetisi dengan melakukan perubahan atau keluar arena kompetisi tanpa dibebani perubahan perbaikan. kedua keputusan tersebut memiliki konsekuensi yang sama beratnya.

Keberhasilan perusahaan bisa dilihat apabila manajemen kualitas berjalan dengan baik, agar produk yang dihasilkan oleh perusahaan tentu baik. Maka apabila terjadi produk cacat, maka masalah tersebut harus diselesaikan dengan segera.

UD Maju Jaya pernah mengalami masalah kualitas produk pada tahun 2013 dimana kualitas tempe yang di hasilkan tidak sesuai yang ingin di capai dan kejadian ini berdampak yang negatif bagi perusahaan. Berdasarkan kejadian diatas maka penelitian terhadap kualitas tempe yang merupakan sumber sebagai bahan penelitian. Maka penelitian ini mengambil judul "Analisis Kualitas Produksi Tempe Dengan Metode Seven Tools di UD Maju Jaya."

\section{II.DASAR TEORI}

\section{A.Definisi Kualitas}

Terdapat beberapa Definisi Kulitas. Berikut definisi dari beberapa pakar TQM, sebagai berikut:

1. Juran, kualitas produk adalah kecocokan penggunaan produk ( for use) untuk memenuhi kebutuhan dan kepuasan pelanggan

2. Crosby, kualitas adalah conformance to requitment, yaitu sesuai dengan yang disyaratkan atau distandarkan.

3. Deming, kualitas adalah kesesuaian dengan kebutuhan pasar. Apabila Juran mendefinisikan kualitas sebagai fitness for use 
dan Crosby sebagai Confomance to requitment,

Mutu (Kualitas) dalam rangka kerangka ISO 9000 didefinisikan sebagai "ciri dan karakter menyeluruh dari suatu produk atau jasa yang mempengaruhi kemampuan produk tersebut untuk memuaskan kebutuhan tertentu".

\section{B. Dimensi Kualitas}

Setelah dipahami definisi kualitas, maka harus diketahui apa saja yang termasuk dalam dimensi kualitas. Menurut sumber buku Manajemen Mutu Terpadu yang di tulis oleh Drs. M.N. Nasution, M.Sc. A.P.U. Maka dimensi kualitas menurut Garvin, mengindetifikasi delapan dimensi kualitas yang dapat digunakan untuk menganalisis karakteristik kualitas barang, yaitu sebagai berikut:

1. Performa (performance)

2. Keistimewaan (features),

3. Keandalan (realibity.

4. Konfirmasi (conformance).

5. Daya tahan (durability)

6. Kemampuan Pelayanan (service ability),

7. Estetika (aesthetics),

8. Kualitas yang dipersepsikan (perceived guality),

\section{Penentuan Standarisasi Produk}

Untuk menentukan jumlah produksi yang akan dilaksanakan, maka salah satu faktor yang perlu diperhatikan adalah production standard, yaitu suatu ukuran yang menjadi patokan dalam melaksanakan kegiatan produksi.

\section{Tujuh Alat Manajemen Kualitas}

Di dalam peningkatan produksi maupun jasa perusahaan yang semakin meningkat, akan diperlukan berbagai metode dan alat bantu (tools) yang bisa digunakan untuk mengeliminasi kegagalan/failure sehingga error dapat di hindari dengan tepat, cepat dan cermat. Peningkatan kualitas produksi dan jasa dapat dilakukan dengan berbagai alat bantu. Salah satunya adalah dengan 7 tools yang merupakan alat dalam pengolahan data untuk peningkatan kualitas, dan 7 new tools merupakan alat bantu dalam memetakan masalah secara terstruktur, guna membantu kelancaran komunikasi pada tim kerja, dan untuk pengambilan keputusan. Dengan menggunakan 7 tools maka problematika yang mengacu pada data dapat terselesaikan dengan cepat dan mudah. Hal ini karena 7 tools masih berlandaskan pada statistika yang dipelajari oleh semua kalangan yang tanpa membutuhkan pendidikan yang tinggi untuk dapat mempelajarinya.

Sedangkan 7 New Tools diperlukan untuk memecahkan masalah secara kualitatif ditingkat management. Jadi apabila kita sudah melakukan analisa 7 Tools, maka kita akan memperoleh data-data factual yang semuannya itu membentuk sebuah pola tertentu yang biasanya digambarkan dan diilustrasikan ke dalam bentuk visual/diagram dan bukan berbentuk laporan tulisan yang membosankan dan membinggungkan. Tujuh alat pengendalian mutu ada dua macam, yaitu old seven of quality (7 alat pengendalian mutu yang lama) atau lebih dikenal dengan Ishikawa's basic seven tools of quality terdiri dari:

1. Flow Chart

2. Check Sheet

3. Histogram

4. Scatter Diagram atau Scatter Plot

5. Control Chart

6. Cause And Effect Diagram

7. Pareto Diagram

Sedangkan New Seven of Quality (7 alat pengendalian mutu yang baru) terdiri dari:

1. The Affinity Diagram

2. The Interrelationship Digraph

3. Tree Diagrams

4. Prioritization Grid

5. Matrix Diagram

6. Process Decision Program Chart

7. Activity Network Diagram

E. Pengertian Tempe

Tempe adalah makanan yang terbuat dari bijibijian, bungkil dan ampas-ampas tertentu yang diolah dengan cara fermentasi dengan menggunakan ragi tempe sehingga tumbuh jamur kapang yang akhirnya membentuk tempe. Kata "tempe" diketahui berasal dari bahasa jawa kuno berdasarkan yang tertulis dalam serat cethini. Tempe telah dibuat di jawa sebelum abad ke 16 dan menyebar ke Eropa melalui Belanda pada tahun 1895 yang akhirnya menyebar ke seluruh dunia. Saat ini tempe menjadi lauk pauk yang populer, murah dan gurih serta kaya gizi sehingga banyak disukai. Hingga di belahan dunia manapun namanya tetap tempe atau tempeh. 


\section{F. Standardisasi Tempe}

Menurut salah satu koran harian kompas, diterimanya usulan Indonesia agar tempe memiliki standar internasional menjadi angin segar bagi kalangan industry. Mereka berkesempatan untuk menembus pasar ekspor kesejumlah negara, terutama yang memiliki kelompok vegetarian cukup banyak. Standardisasi menjadi jaminan bagi konsumen akan kelayakan produk yang mereka konsumsi. Usulan Indonesia tersebut diterima oleh Codex, yakni wadah bersama antara Organisasi Pangan dan Pertanian $(F A O)$ dengan Organisasi Kesehatan Dunia $(W H O)$. Usulan tersebut disampaikan pada sidang ke-34 Codex di Geneva, Swiss, 4-9 Juli 2011, sejak itu standardisasi internasional untuk tempe pun disiapkan. Indonesia menjadi salah satu negara yang ditugasi sebagai tim penyusun standarlisasi. Badan Standarlisasi Nasional sebagai tim yang terlibat menyatakan standar internasional dibuat secara bertahap. Pertama untuk kawasan Asia Pasifik, kemudian melebar ke kawasan Eropa, Afrika, dan kawasan lainnya.

\section{G. Ciri Tempe yang Baik}

Menurut Kasmidjo (1990) tempe yang baik harus memenuhi syarat mutu secara fisik dan kimiawi, tempe dikatakan memiliki mutu fisik jika tempe itu sudah memenuhi ciri-ciri tertentu. Ciri-ciri tempe yang baik sebagai berikut:

1. Warna Putih

Warna putih ini disebabakan adanya miselia kapang yang tumbuh pada permukaaan biji kedelai.

2. Tekstur Tempe Kompak

Kekompakan tekstur karena juga disebabkan oleh miselia \pm miselia kapang yang menghubungkan antara biji-biji kedelai. Kompak tidaknya tekstur tempe dapat diketahui dengan melihat lebat tidaknya miselia yang tumbuh pada permukaaan tempe. Apabila miselia tampak lebat, hal ini menunjukkan bahwa tekstur telah membentuk masa yang kompak begitu juga sebaliknya.

3. Aroma Dan Rasa Khas Tempe Terbentuk aroma dan rasa yang khas pada tempe disebabkan terjadinya degradasi komponen- komponen dalam tempe selama berlangsungnya proses fermentasi.

\section{H. Ciri Tempe yang Tidak Jadi}

Pada pembuatan tempe terutama pada saat proses fermentasinya, kondisinya harus higienis dan bersih sehingga pembuatan tempe akan berhasil, karena fermentasi tempe hanya terjadi pada lingkungan yang higienis, berikut ini adalah ciri-ciri tempe yang tidak jadi (fermentasi tidak berhasil) yaitu:

1. Tempe tetap basah.

2. Jamur tumbuh kurang baik.

3. Tempe berbau busuk

4. Ada bercak hitam dipermukaan tempe.

5. Jamur hanya tumbuh baik disalah satu tempat.

\section{III.METODE PENELITIAN}

\section{A.Ruang Lingkup Penelitian}

Berdasarkan penelitian yang dilakukan, ruang lingkup penelitian dibatasi berdasarkan tempat dan objek penelitian sebagai berikut:

1. Tempat Penelitian

Penelitian bertempat UD Maju Jaya Jl. Kenanga 3 Rt 02 Rw 04 No 29, Serpong, Tangerang Selatan, Banten 15325, Indonesia. Telepon (021) 93369652.

2. Objek Penelitian

Objek penelitian adalah produk tempe pada UD Maju Jaya.

\section{B. Metode Penelitian}

Dalam melakukan penelitian, metode yang digunakan adalah sebagai berikut:

1. Metode Analisis, yang terdiri dari:

a. Metode Deskriptif

Metode ini menggambarkan data masalah yang ada dan berkembang pada saat penelitian dilakukan (data aktual yang kemudian dianalisis untuk menguji hipotesis yang telah dilakukan) melihat keadaan serta mengumpulkan beberapa data berdasarkan fakta-fakta yang ada di perusahaan.

b. Metode Historis

Mengumpulkan data perusahaan baik data perusahaan pada masa kini dan 
data perusahaan pada masa lalu untuk melihat perkembangan perusahaan.

2. Lokasi dan Waktu Penelitian

a. Lokasi

Penelitian ini dilakukan di UD Maju Jaya yang memproduksi tempe yang berlokasi di J1 Kenanga Rt 02 Rw 04 N0 29 Serpong, Tangerang Selatan, Banten, Indonesia. Telepon (021) 933696552.

b. Waktu Penelitian

Penelitian mulai dilakukan pada bulan Januari 2013 sampai dengan Desember 2013.

C.Teknik Pengumpulan Data

Teknik pengumpulan data yang dilakukan dalam penelitian ini terdiri atas:

\section{Data Primer}

Data primer merupakan data yang didapatkan langsung dari sumbernya, diamati dan dicatat untuk pertama kalinya. Adapun cara-cara yang dilakukan dalam pengumpulan data primer ini :

a. Observasi Lapangan

Teknik ini mengandalkan pengumpulan data dengan cara turun langsung ke lapangan dengan tujuan mendapatkan data actual yang diperlukan dalam penelitian ini.

\section{b. Interview}

Interview adalah teknik pengumpulan data dengan cara wawancara langsung dengan narasumber yang mempunyai keterkaitan dengan penelitian ini.

c. Dokumentasi

Dokumentasi merupakan dokumen, catatan atau arsip perusahaan yang diambil sebagai sumber dari penelitian yang dilakukan.

\section{Data Sekunder}

Data sekunder merupakan kumpulan data yang diperoleh dengan cara hasil studi ke perpustakaan. Studi ke perpustakaan ini dilakukan untuk mendapatkan dasar pemikiran, konsep atau landasan teori dari literatur-literatur yang semuanya berfungsi pula sebagai pengontrol jalannya penelitian. Juga sebagai bahan perbandingan dalam memahami kondisi perusahaan dan panduan dalam pemecahan masalah.

Dari hasil pengamatan pada gambar 4.7 dapat diketahui bahwa jenis gagal tempe terbesar yang terjadi pada hasil produksi tempe yaitu pada periode bulan Januari 2013 sampai dengan Desember 2013 adalah tempe tetap basah. Berdasarkan diagram pareto tingkat kegagalan produk tempe yaitu pada tempe tetap basah jumlah presentase gagal tersebut yaitu $56 \%$ dengan presentase kumulatifnya sebesar $56 \%$, dan jumlah kegagalan produk terbesar kedua yaitu tempe bercak hitam dengan presentase $44 \%$ dengan presentase kumulatifnya 100\%. Jadi perbaikan yang harus dilakukan terlebih dahulu yaitu pada tempe tetap basah, hal ini dikarenakan gagal tersebut merupakan jumlah gagal tempe terbesar dibandingkan dengan gagal yang lainnya.

\section{IV.HASIL DAN PEMBAHASAN A.Keadaan Perusahaan Sesudah Menggunakan Metode Seven Tools}

Setelah mengaplikasikan metode seven tools maka hasil produksi dapat dilihat pada tabel 4.11 bahwa hasil produksi dalam waktu setahun yaitu bulan Januari 2013 sampai dengan bulan Desember 2013 dengan total yaitu 79271 .

Tabel 4.11 Hasil Produksi 


\begin{tabular}{|c|c|c|} 
NO & BULAN & JUMLAHPRODUKSI TEMPE \\
\hline 1 & Januari & 6932 \\
\hline 2 & Februari & 6240 \\
\hline 3 & Maret & 6728 \\
\hline 4 & April & 6811 \\
\hline 5 & Mei & 7042 \\
\hline 6 & Juni & 6721 \\
\hline 7 & Juli & 6952 \\
\hline 8 & Agustus & 5411 \\
\hline 9 & September & 6696 \\
\hline 10 & Oktober & 6477 \\
\hline 11 & November & 6639 \\
\hline 12 & Desember & 6622 \\
\hline & Total & 79271 \\
\hline & $($ Sumber: Pengoanan 59641$)$ \\
\hline
\end{tabular}

(Sumber: Pengolahan Sendiri)

Sedangkan dari data tabel 4.12 dapat diketahui jumlah total tempe gagal Januari 2013 sampai dengan bulan Desember 2013 yaitu 543, dan pada bulan Februari 2013 dengan jumlah gagal 95 merupakan jumlah gagal yang terbanyak

Tabel 4.12 Hasil Produksi Tempe Gagal

\begin{tabular}{|c|c|c|}
\hline $\mathrm{N}_{0}$ & BULAN & JUMLAH TEMPE GAGAL \\
\hline 1 & Januari & 38 \\
\hline 2 & Februari & 95 \\
\hline 3 & Maret & 0 \\
\hline 4 & April & 58 \\
\hline 5 & Mei & 66 \\
\hline 6 & Juni & 0 \\
\hline 7 & Juli & 37 \\
\hline 8 & Agustus & 43 \\
\hline 9 & September & 64 \\
\hline 10 & Oktober & 33 \\
\hline 11 & November & 48 \\
\hline 12 & Desember & 61 \\
\hline & Total & 543 \\
\hline
\end{tabular}

(Sumber: Pengolahan Sendiri)

Urutan-urutan proses pembuatan tempe secara lebih jelas sebagai berikut:

\section{Pembersihan}

Proses pembersihan meliputi pemisahan bagian-bagian yang kotor dan kacang yang bermutu tidak bagus, oleh karena itu oleh karena itu proses pembersihan ini harus benar-benar di peroleh kacang yang bersih dari ampas dan kotoran lainnya.

2. Pengecekan

Proses pengecekan dilakukan setelah pembersihan

3. Perendaman

Setelah bersih kacang kedelai di rendam selama 2 jam sampai membesar bentuk kacang kedelai, tujuan perendaman ini adalah untuk melunakkan kacang, dan air yang digunakan tidak boleh mengandung garam dan minyak.

4. Perebusan

Proses perebusan selama \pm 2 jam sampai matang, setelah matang di lakukan 
perendaman yang ke dua selama sehari semalam, setelah direndam kacang kedelai dimasukkan ke dalam mesin penggilingan sampai kacang kedelai pecah. Setelah digiling dilakukan pencucian yang kedua dan penyaringan, tujuannya untuk memisahkan kulit kacang kedelai.

5. Peragian

Setelah di cuci di lakukan peragian dengan cara mencampurkan ragi tempe kepada kacang kedelai, lalu kacang kedelai ditiriskan selama beberapa jam.

6. Pencetakan

Campuran kacang kedelai yang sudah di tiriskan siap untuk di cetak ke dalam cetakan dengan menggunakan plastik yang sudah di lubangi dengan jarum.

7. Penyimpanan

Setelah di cetak kacang kedelai di simpan di rak penyimpanan selama 2 hari, tujuannya untuk mengubah kacang kedelai menjadi tempe.

8. Pemasaran

Setelah 2 hari di simpan dan menjadi tempe maka pada hari ke 3 siap untuk dipasarkan.

\section{KESIMPULAN}

Kesimpulan dalam penelitian ini adalah sebagai berikut:

1. Kualitas produksi tempe di UD Maju Jaya pernah mengalami masalah kualitas produk pada tahun 2013 dimana hasil produksi 79447 dengan total gagal tempe 7191. Dengan menganalisis menggunakan Metode Seven Tools maka dapat dilihat bahwa tempe gagal diluas batas kontrol atas pada bulan Maret 2013 dan Juni 2013, setelah menggunakan seven tools maka hasil produksi 79271 dengan total gagal tempe 543.

2. Mengaplikasikan kualitas produksi tempe di UD. Maju Jaya adalah dengan menggunakan seven tools maka dapat diketahui melalui check sheet hasilnya tempe gagal dalam setahun disebabkan oleh jenis tempe tetap basah dengan jumlah 63, flow chart dapat dilihat langkah proses terbanyak ialah pengecekan, perendaman, pelubangan dan pembersihan dilakukan sebanyak 2 kali, histogram berbentuk skewed artinya distribusi tidak normal dengan jumlah tertingi 35 pada sell 4, Hasil korelasi yaitu 0,0030. Control chart dengan BKA= 85,9196, Garis Sentral= 62,25 dan $\mathrm{BKB}=38,5804$. Dengan cause and effect yang menyebabkan kegagalan adalah faktor manusia, sedangkan dari diagram pareto dapat dilihat kegagalan (tempe tetap basah) merupakan yang tertinggi dengan presentase gagal yaitu $56 \%$ dengan presentase kumulatif $56 \%$.

\section{DAFTAR PUSTAKA}

Drs.Nasution,M.N,M.Sc Manajemen Mutu Terpadu cetakan pertama, Jakarta: 2001

Drs. Yamit Zuliat, M.Si, Manajemen Kualitas Produk dan Jasa cetakan keenam, Yogyakarta: 2013

Ginting Rosnani, Sistem Produksi, cetakan pertama 2007

Ir Nasution Arman Hakim, M.Eng, Manajemen Industri, Yogyakarta 2006

Purnomo Hari, Pengantar Teknik Industri, edisi kedua, Yogyakarta 2004

Render Barry dan Jay Heizer, PrinsipPrinsip Manajemen Operasi edisi pertama, Jakarta 2001.

Perpustakaan Universitas Pamulang Oki Irawan, 200580076, Analisis Pengendalian Kualitas Pada Produksi Tempat Telur (EGGS-TRAY) DI PT.MENSANA ANEKA SATWA skripsi. Pamulang: 2010 
Soewadji Jusuf,MA. Pengantar Metodelogi Penelitian cetakan pertama Jakarta: 2012

http//teknikelektronika.com/pengertiananalisis-korelasisederhana-rumusperson/Jumat 19-12-2014/ Jam 05:02

http//herysetiawanhf109019.blogspot.com/20 14/06/07-alat-pengendaliankualitas.html/sabtu-04-10-2014/Jam 02:pm 